\title{
AC Fault Ride Through of Modular Multilevel Converter VSC-HVDC Transmission Systems
}

\author{
Olusegun Olowookere, Spyros Skarvelis-Kazakos, Yehdego Habtay and Steve Woodhead \\ Faculty of Engineering and Science \\ University of Greenwich, Medway,UK \\ O.Olowookere@gre.ac.uk
}

\begin{abstract}
This paper discusses the AC fault ride through of two terminal modular multilevel converter (MMC) VSC based HVDC integration of combined offshore wind and wave farms. The combined offshore wind and wave farms are modelled as a controllable three phase voltage source connected to a 600MVA, $460 \mathrm{kV} / 370 \mathrm{kV}$ transformer. A 31- level MMC has been selected because of acceptable harmonic attributes. Two $300 \mathrm{kV}$ DC submarine cables with length of $100 \mathrm{~km}$ have been employed in this study. A voltage source has been connected in series with an inductive resistive circuit to give a short circuit ratio of 3.5. This paper finally presents a comparative simulation analysis of hysteresis based and PI based DC voltage controller for fault ride through (FRT) capability. The analysis showed that the PI method resulted in smaller overshoots and dips. A high switching frequency PWM based electromagnetic transient (EMT) model in MATLAB/Simulink was developed for the analysis.
\end{abstract}

Index Terms-PI, Hysteresis, FRT, VSC, HVDC, MMC, EMT.

\section{INTRODUCTION}

Wind and wave energy are promising renewable energy sources in the United Kingdom [1]. They are predicted to form an integral part of the EU electricity mix towards ensuring $15 \%$ of its electricity demand comes from renewables [2]. Emphasis has been placed on the possibility of integrating offshore wind power with other renewable power sources, particularly wave power [3-4]. Wind power suffers from intermittency while wave power suffers from variability [5-6].

There are certain benefits in co-locating wind and wave farms [2]. These include effective utifization of space, easier procurement of planning permission, reduced installation cost, reduced output power variability and minimized intermittency [7]. Comparison of the power generation profile of a wind farm on its own and that of combined wind and wave energy farms, indicates that the power generation of the combined arrangement is more reliable than a single wind farm [8]. However, the AC grids formed by connecting offshore wind and wave farms can be weak [9].

Due to these weak AC grids, VSC based high voltage direct current (HVDC) transmission systems are the adopted alternative to conventional high voltage alternating current (HVAC) for long distance power transmission of wind and wave farms. VSC based HVDC transmission systems possess fast modulation and high power transfer capabilities [10].
In addition, the cost of submarine HVAC transmission is higher than HVDC transmission for distances above 55 -70 $\mathrm{km}$ [11]. Other challenges of AC transmission relate to the inductance and capacitance of the conductors, which have to be compensated above a certain distance $[7,11]$. On the other hand, HVDC transmission possesses advantages such as: asynchronous system interconnections, high power delivery, reduced transmission losses and improved dynamic voltage stability at the converter station [7,9]. There are two main types of HVDC transmission technologies: Line commutated converter (LCC) based HVDC systems and Voltage source converter (VSC) based HYDC systems [7, 9, 10].

2-level and 3-level VSC topologies had been employed for HVDC transmission networks until recently. However, their applications were restricted to a $400 \mathrm{MW}$ rating because of high switching losses caused by the use of pulse width modulation technique [12].

The Modular Multi-level Converter (MMC) topology is a new HVDC converter technology which is very promising for high voltage applications [13-14]. MMC ensures a high quality voltage waveform from switching a number of voltage levels producing a smooth step - like output [13]. The introduction of MMCs has enabled the increase of converter station efficiency [12]. This topology also allows for lower switching frequency $[12,13]$. The advantages of MMCs are derived from their modular structure which enables higher voltages from several modules [14], removing the need for switches to be connected in series [12]. MMC stations in a VSC based transmission system possess stronger capacitive features than conventional VSC stations [15].

Modulation methods employed in multilevel modular converters include high frequency carrier based PWM and space vector PWM [16-17]. With the MMC-VSC based transmission being the preferred choice for UK power system, this paper will investigate the comparison of two DC chopper controllers for resistor based power dissipation when an AC fault occurs.

In this paper, a comparative study of two controllers for chopper resistor based DC overvoltage for fault ride through of MMC VSC HVDC systems is presented. The simulation study was carried out using MATLAB /SIMULINK to demonstrate the effectiveness of both controllers with a 31level MMC based VSC-HVDC system. Fig. 1 shows the MMC based transmission layout for the study. 


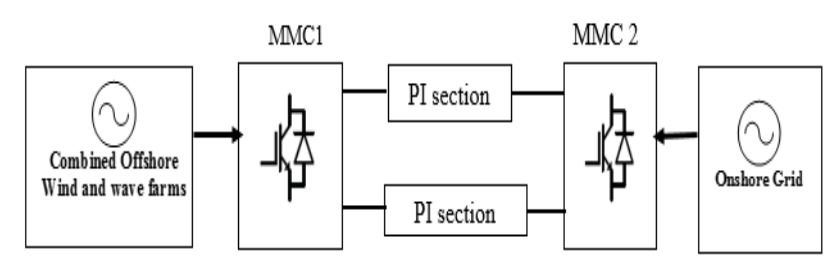

Fig. 1: MMC based Transmission layout

\section{FAULT RIDE THROUGH}

Despite the benefits in the co-location of wind and wave farms, challenges still exist. The main challenge is that both power generation technologies are at different developmental stages [18]. However, there are also particular challenges in implementing the integration. One of the integration challenges according to [19-21] include compliance with grid code requirements such as voltage and frequency control.

The grid code requirements relate to: power fluctuations, voltage variations, frequency response, power flow, inertia response, reactive power capability and fault ride through (FRT) capability [22]. Fault ride through capability refers to the ability of the converter station to remain connected to the DC grid when a fault occurs in the AC network, and is challenging to achieve [23, 24].

HVDC-VSC is a technology capable of operating at low AC voltage, compared to its nominal [25-26]. AC faults can have a potentially severe impact on HVDC networks, because of the tendency of the transient voltage of the capacitors to increase [27, 28]. VSC-HVDC networks must have fault ride through capability, to deal with AC network disturbances [29]

Without FRT provision, when a short circuit fault oceurs at the onshore grid side, an active power imbalance occurs on the HVDC network. This effect can cause the network to collapse.

The FRT characteristics of combined offshore wind and wave farms, like other conventional power plants, are required to comply with grid codes as stated in [20,22]. FRT strategies according to literature [30-42] can be divided into the following methods:

1) Power reduction;

2) DC chopper based energy storage;

3) DC chopper based resistor.

The power reduction method refers to a way of minimizing the active power injection to accommodate the AC fault's effect on the converters. The reduction method can be subdivided into [30-42]:

1) Communication between DC grid and wind turbines;

2) Voltage / Frequency modulation of converter station;

3) Blocking of the converter.

The DC chopper based energy storage methods are used for back to back power electronic converters. Applications where they are employed include: doubly fed induction generators and synchronous generators.
The DC chopper based resistor method is the easiest to implement and is generally regarded as robust. This strategy leaves the wind and wave farms unaffected when there is an onshore fault [43]. A DC resistor is used to dissipate the excess DC power during AC faults. This method permits quicker frequency response and control of unexpected power.

This method has been considered in this paper to control the excess DC voltage caused by a three phase fault in the onshore grid with MMC based VSC converters.

\section{SIMULATION MODEL}

\section{A. MMC VSC HVDC transmission system for combined offshore} wind and wave farms

The simulation details of a point to point MMC VSCHVDC system are presented. The combined offshore wind farm and wave farm are modelled as a controllable three phase voltage source connected to a $600 \mathrm{MVA}, 460 \mathrm{kV} / 370 \mathrm{kV}$ transformer. A 31- level MMC has been selected because it produces fairly acceptable harmonic attributes [44]. 10\% ripple voltage was applied in the design calculation for the sub module capacitors [45]. A VSC-HVDC transmission system rated at $1 \mathrm{GW}+300 \mathrm{kV}$ has been considered, as suggested by National Grid [46]. Two 300kV DC submarine cables and a cable length of $100 \mathrm{~km}$ have been employed in this study. A voltage source has been connected in series with an inductiveresistive circuit to give a short circuit ratio of 3.5 and a phase reactor of $15 \%$. The active power from the combined offshore wind and wave farms is injected into the transmission link through the MMC 1 station. DC link voltage is maintained by MMC 2 which also controls the onshore AC voltage.

The nominal DC link voltage was $600 \mathrm{kV}$ and the DC cable parameters have been defined on a $600 \mathrm{kV} / 1 \mathrm{kA}(600 \mathrm{MW})$ base. DC damping resistors of $600 \Omega(600 \mathrm{MW}$ at $600 \mathrm{kV})$ were connected to the two grid side VSC DC terminals through controllable power switches (IGBTs). The DC voltages at the onshore ends were maintained at $600 \mathrm{kV}$. A three phase to ground fault was applied to the onshore AC network $1 \mathrm{~s}$ into the simulation, which lasted for $140 \mathrm{~ms}$, in accordance with United Kingdom grid code stipulations [47].

\section{B. MMC-VSC HVDC control}

The MMC VSC HVDC system has three control loops on each side of the AC grid. On the wind and wave farm side, the control loops are: the active power and voltage controller loops, the inner current control loop and the MMC modulator. On the grid side, the control loops are: the DC voltage and AC voltage controller loops, the inner current control loop and the MMC modulator. Fig. 2 shows the MMC modulator implementation. 


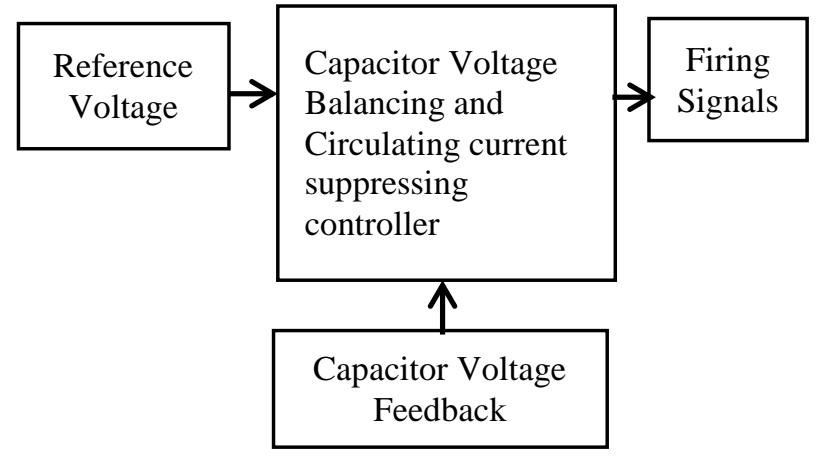

Fig. 2: MMC modulator implementation

\section{Hysteresis based FRT controller}

This control strategy attempts to constrain the DC voltage within a hysteresis band around a reference voltage. The measured grid DC voltage is compared with the reference through hysteresis comparators.

A fixed band DC voltage FRT controller is employed for regulating the voltage. The hysteresis controller produces a continuous output voltage spectrum with a wide frequency range, which is one of the demerits of this controller [48]. The Hysteresis controller has a quick response to fast variations in reference voltage. The voltage error $\Delta$ is applied and $h$ is the height of the hysteresis loop. The variable of the controller is a. The controller's characteristic is expressed as [49]:

$$
\mathrm{a}=\left\{\begin{array}{cc}
0 & \text { if } \Delta<-\frac{\mathrm{h}}{2} \\
1 & \text { if } \Delta>+\frac{\mathrm{h}}{2}
\end{array}\right.
$$

In this controller, the switching frequency is varied according to the DC grid voltage and the conditions of operation. This variable switching frequency has the tendency to create harmonics which renders its application restricted to low power applications. A hysteresis controller configuration has an on or off switch logic.

\section{PI-based FRT controllers}

A PI controller is a commonly used feedback control device, which attempts to maintain the control parameters around given set points. Set point regulation is normally achieved through the use of PI control. PI control effectively combines the regulation of proportional and integral control to instantaneously keep system changes within specified limits.

If $\mathrm{P}$ is the controller output, ep is the error of the controlled variable from the set point, $\mathrm{Kp}$ is the proportional gain, $\mathrm{Ki}$ is the integral gain and Px (0) is the controller's output at the start of the operation. The analytical expression is given in (1) below as:

$$
\mathrm{P}=\mathrm{Kp} * \mathrm{ep}+\mathrm{Ki} \int(\mathrm{ep} * \mathrm{dt})+\mathrm{Px}(0)
$$

The combined effect of the proportional and integral values is critical to the response speed and the steady state error. The tuning or adjustment of the proportional and integral values is carefully undertaken in order to obtain the required control.
A PI controller processes the error between the reference and DC grid voltages and has the capability of zero error at steady state if the reference is a continuous signal [48]. In this study the PI controller is tuned via the pole -zero placement method. The PI controller parameters must be optimally selected in order to ensure that the closed loop voltage overshoot is minimized [50].

\section{E. AC fault ride through simulation configuration}

The configuration parameters listed below have been selected in accordance with [32]. The ultimate gain of the PI controller $(\mathrm{Ku})$ and the oscillation period $(\mathrm{Tu})$ were 0.00333 and 0.667 respectively. The values of the PI controller gains used were $\mathrm{Kp}=0.0015$ and $\mathrm{Ki}=0.006$ while the hysteresis limits were $\pm 0.01 \mathrm{pu}$. The DC voltages at the onshore ends were maintained at $1.05 \mathrm{pu}$. A hysteresis band of $1.06 \mathrm{pu}$ to $1.08 \mathrm{pu}$ was applied for the hysteresis controller while the set point of 1.06pu was employed for the PI controller. A three phase to ground fault was applied to the onshore AC network $1 \mathrm{~s}$ after the start of the simulation, which lasted for $140 \mathrm{~ms}$.

\section{F. AC fault ride through methodology}

The power dissipation method employed in this study, involves DC damping resistors placed very close to the DC side of the onshore VSC stations. This approach is simple and very reliable [51]. When there is a DC over voltage, the DC resistors are switched in so that the VSC stations at the offshore end can continue operation even during the fault condition. This method requires extra cost for the installation of the resistors and the switching arrangement. As long as the resistors are sized according to the system rating, the trapped DC energy is dissipated by the resistors through the power switch control [51].

When an AC fault occurs at the onshore station, power exchange breaks down between the DC grid and the converter. Hence, power produced from the combined wind and wave farms should be regulated to respond to the demand of the onshore converter. This implies that the tendency of the DC link voltage rise to can be counteracted by the shunt resistor connected very close to the converter station.

\section{RESULTS AND DISCUSSION}

The MMC FRT simulation results of this study are shown in Figs. 3a- 3d. Figs. 3a and 3b show the results for a PI based and a hysteresis based controller for onshore grid voltage. Figs. $3 \mathrm{c}$ and $3 \mathrm{~d}$ show the results of a PI based and a hysteresis based controller for onshore grid current.

Comparing Figs. 3(a) with 3(b), the PI based response produced a voltage rise to $1.0857 \mathrm{pu}$ while the hysteresis controller produced a rise in voltage to $1.1 \mathrm{pu}$. Thus the PI controller achieved a $0.0143 \mathrm{pu}(14.3 \%)$ reduction in voltage overshoot when compared to the hysteresis controller. The effect of $14.3 \%$ reduction shows that the DC braking resistor and VSC controller are subject to less stress with the PI controller than the hysteresis controller. Comparing Figs. 3(c) with 3(d) the PI based controller resulted in a drop in current to $-750 \mathrm{~A}$, while the hysteresis controller resulted in a drop in current to $-958 \mathrm{~A}$. 


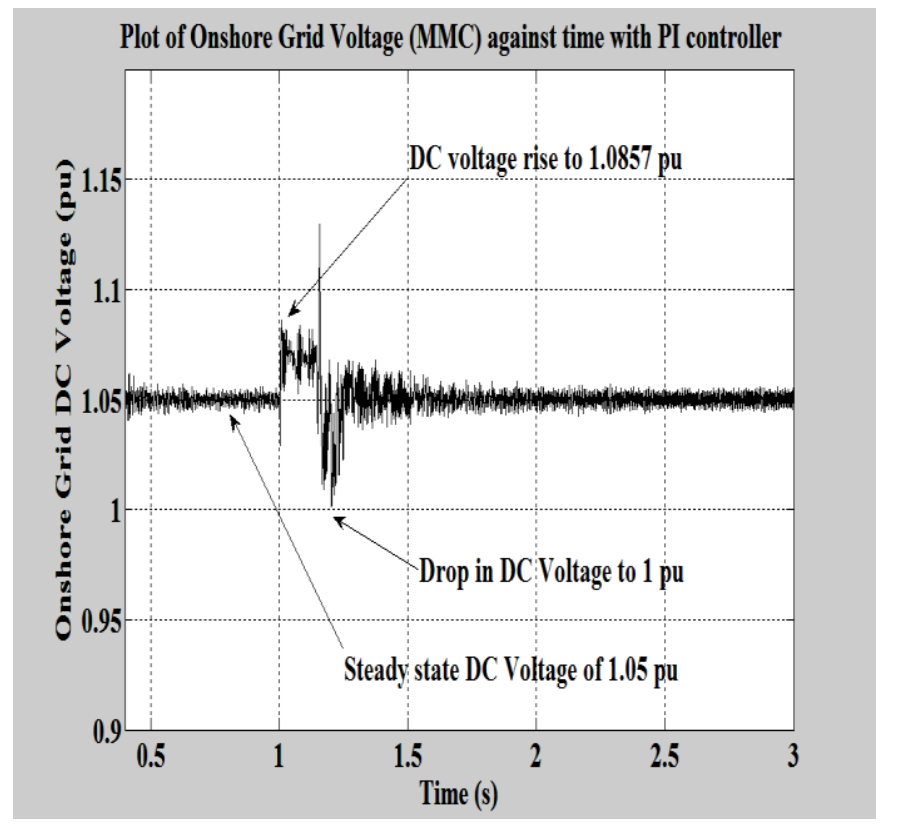

Fig. 3a. Onshore Grid Side DC Voltage (PI)

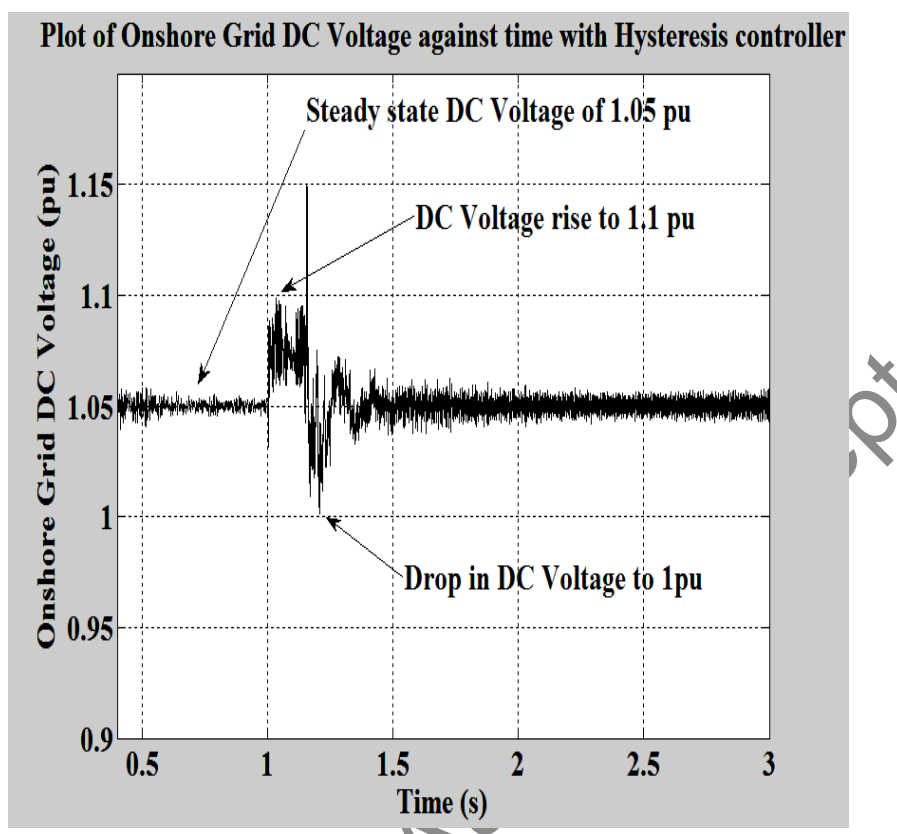

Fig. 3b. Onshore Grid Side DC Voltage (PI)

The choice of the DC grid overvoltage control is critical due to the responses of the DC voltage and DC current in terms of overshoots and dips. Dips and overshoots carry risks capable of reducing the life span of transmission cables due to insulation failures.

The selection of the protection method influences the failure rate of DC submarine cables [46]. Considering that offshore cables are submarine based, there are two main indices that must be considered: mean time to failure (MTTF) and mean time to repair (MTTR) [46]. With these two indices, the availability (A) of the DC cable can be computed as indicated in (2) [46].

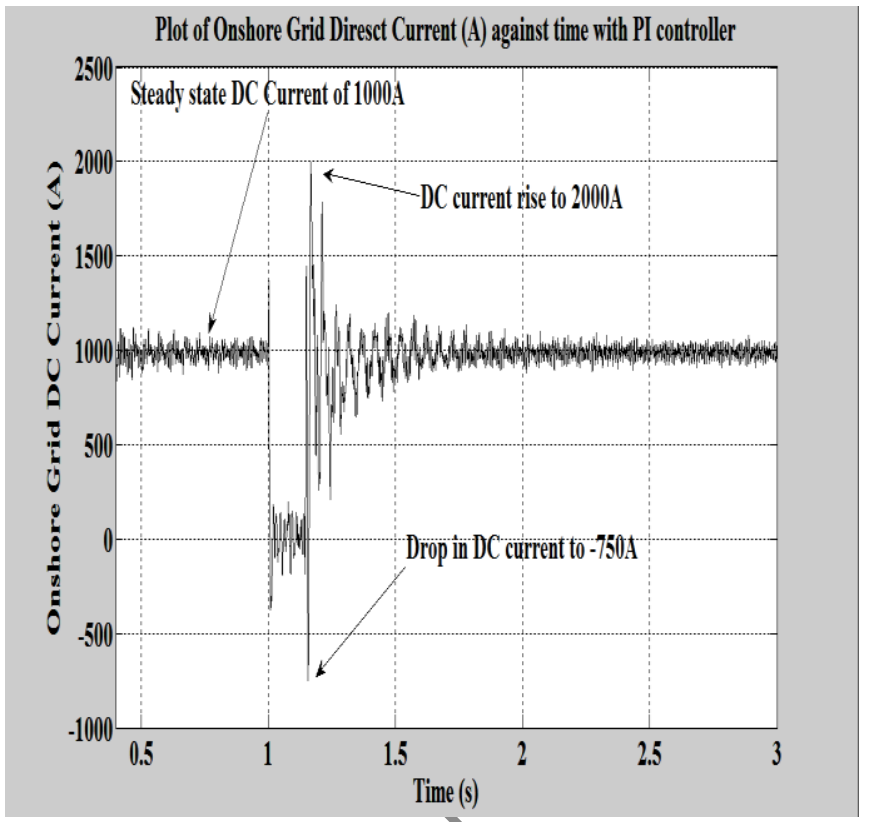

Fig. 3c. Onshore Grid Side DC Current (PI)

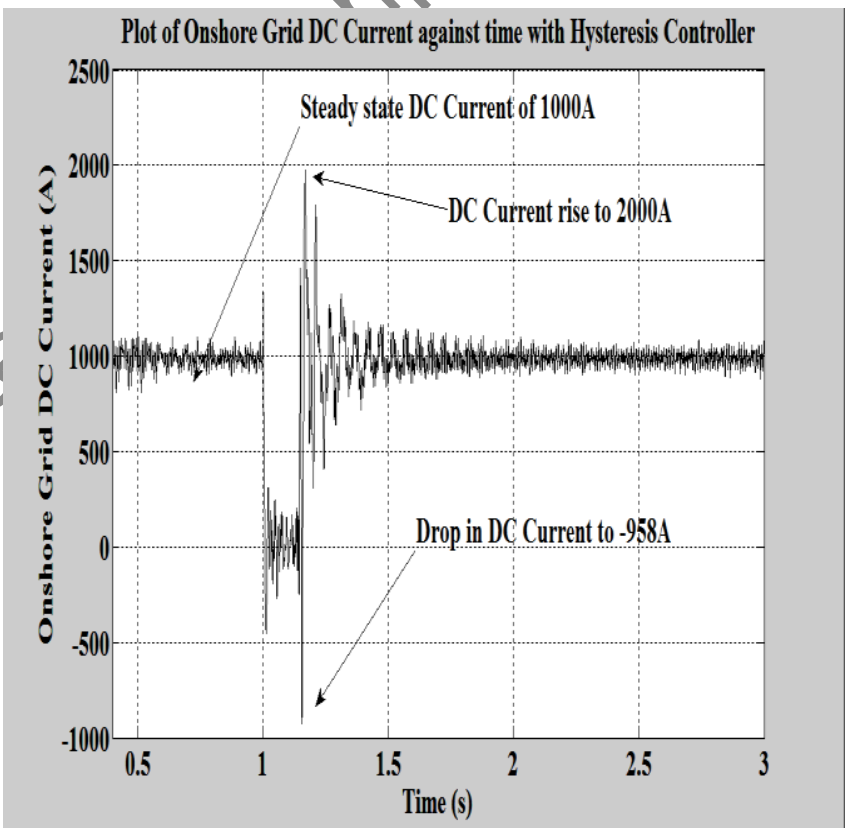

Fig. 3d. Onshore Grid Side DC Current (Hysteresis)

$$
\mathrm{A}=\frac{\mathrm{MTTF}}{\mathrm{MTTF}+\mathrm{MTTR}}
$$

The determination of the indices above defines the availability of the transmission scheme. With the reduction in overshoot and dips, there will be a minimised MTTR and MTTF, which will translate to increased availability of the submarine cable for smooth operation of the offshore wind and wave farm. Protection of the DC cables is therefore crucial for the smooth operation of the transmission system. 


\section{CONCLUSION}

This paper has examined the DC voltage and active power balancing of a point to point VSC-based transmission system employed for the integration of large offshore wind and wave farms. FRT in HVDC transmission is crucial due to the fact that commercial HVDC circuit breakers are not yet available. FRT capability is also a major technical issue for wind/wave farm integration. In this paper, a DC damping resistor has been employed for a simulation study, as the most convenient method for achieving onshore AC fault ride through. Two controller designs have been examined: PI controller and hysteresis controller. The comparative study shows that the PI controller is suitable for cases where fixed varying switching is required for the control parameter. However, the PI controller requires effort for tuning and there can be some overshoot above the set point. Overall, for the fault ride through application, the PI controller responses were superior to those of the hysteresis controller. Simulation results in this report are useful for studying the behavior of the DC voltage overshoots and dips, which are capable of increasing transient energy. Voltage overshoot conventionally limits DC voltage of DC cables. The reduction in overshoots reduces fatigue on the DC cables, which increase the life expectance.

\section{REFERENCES}

[1] Department of Energy and climate change, "UK Renewable Energy Roadmap Update 2013,', .

[2] C. Perez-Collazo et al, "Synergies for a wave - wind energy concept," EWEA offshore, Frankfurt, Germany. The European Wind Energy Association, 2013

[3] S. E. B. Elghali, R. Balme, K. L. Saux, M. E. H. Benbouzid, J. F. Charpentier, and F. Hauville, "A simulation model for the evaluation of the electrical power potential harnessed by a marine current turbine," IEEE Journal of Oceanic Engineering, vol. 32, no. 4, pp. 786-797, October 2007

[4] W. M. J. Batten, A. S. Bahaj, A. F. Molland, and J. R. Chaplin, "Hydrodynamics of marine current turbines," Renewable Energy, vol. 31, no. 2, pp. 249-256, February 2006.

[5] Z. X. Weng, L. B. Shi, Z. Xu, L. Z. Yao, Y. X. Ni, and M Bazargan, "Effects of wind power variability and intermittency on power flow," IEEE Power and Energy society general meeting, pp. 1, 7, July 2012.

[6] G. Roesler, "Wave spectra, wave conversion device-performance, and integration into electricity markets,"' IEEE conf., pp. 1-7, September 2011

[7] A. Reidy and R. Watson, "Comparison of VSC based HVDC and HVAC Interconnections to a Large Offshore Wind Farm,' IEEE Power Engineering Society General Conference, pp. 1-8, June 2005.

[8] M. H. Okba, M. H.Saled, M. Z. Mostafa, and T. M. Abdel-Moneim, "High voltage direct current transmission-A review, part I," IEEE conf., pp. 1-7, May 2012.

[9] E. Spahić and G. Balzer, "Offshore Wind Farms - VSC-based HVDC Connection,’’ IEEE Power Technology Conference, pp. 1-6, June 2005.

[10] M. H. Okba, M.H.Saled, M.Z. Mostafa, and T. M. Abdel-Moneim, "High voltage direct current transmission-A review, part II,' IEEE conf., pp. 1-7, May 2012.

[11] A. B. Mogstad, M. Molinas, P. K. Olsen, R. Nilsen, "A power conversion system for offshore wind parks, " IEEE Conference on Industrial Electronics, pp. 2106-2112, November 2008.

[12] U. N. Gnanarathna, S. K. Chaudhary, A. M. Gale, and R.Teodorescu, "Modular multi-level converter based HVDC system for grid connection of Offshore Wind Power Plant," in IET Conference on AC and DC Power Transmission, pp. 1-5, October 2010.

[13] S. Kouro et al, "Recent advances and industrial applications of multilevel converters," IEEE Transaction on Industrial electronics, vol 57, no. 8, pp. 2553-2580, July 2010.
[14] H. Byung Moon, and J. Jong Kyou, "Switching - level simulation model of MMC-based back-to-back converter for HVDC application,", IEEE conf., pp. 937-943, May 2014.

[15] L. Xuan, S. Qiang, L. Wenhua , and M. Yulong, "Study on fault ridethrough capability of wind farm integration using MMC-HVDC,' in Power System Technology International Conf., pp. 2596-2601, October 2014.

[16] N. A. Rahim and J. Selvaraj, "Multistring Five-Level Inverter with Novel PWM Control Scheme for PV Application," IEEE Trans. Ind. Electrons., volume 57, pp. 2111-2123, (2010).

[17] B. P. McGrath and D. G. Holmes, "Multi-carrier PWM strategies for multilevel inverters," IEEE Trans. Ind. Electrons., volume 49, No. 4, pp. 858-866, (2002).

[18] T. Lewis, "The status of ocean energy development in Europe and some current research questions," IEEE conf., pp. 1-6, September 2011.

[19] V. K. Jon, D. Martin Heyman, F. Olav B, L. G. Javier, and A. Del Pozo, "Grid connection and macro - system integration of combined wind and wave devices,' Ecological Vehicles and Renewable Energies ( EVER) Conf., pp. 1-7, March 2013.

[20] R. S. Kunte, C. Pallem, and D. Mueller, "Wind plant reactive power and voltage compliance with grid codes,' IEEE PEMD conf., pp. 1-4, July 2012.

[21] National Grid Electricity Transmission - UK "The Grid Code", Issue 3, Revision 19, United Kingdom, 1st January 2007, Website: http://www.nationalgrid.com/uk/Electricity/Codes/gridcode/gridcodedo c s/, accessed March 2015.

[22] A. Arulampalam, G. Ramtharan, N. Jenkins, and V.K. Ramachandaramurthy, "Trends in wind power technology and grid code requirements,' Industrial and Information systems conf., pp. 129134, August 2007.

[23] J. Maneiro, S Tennakoon, C. Barker, and F. Hassan, "Energy diverting converter topologies for HVDC transmission systems," IEEE Power Electronics and Application European Conf., pp. 1-10, Sept. 2013.

[24] L. Xuan, S. Qiang, L. Wenhua, and M. Yulong, "Study on fault ride through capability of wind farm integration using MM-HVDC,' IEEE conf., pp. 2596-2601, October 2014.

[25] N. Qin, S. You, Z. Xu, and V. Akhmatov, "Offshore wind farm connection with low frequency AC transmission technology," IEEE conf., pp. 1-8, July 2009.

[26] Y. Wang, X. Su, and X. Han, "Fault ride through control of the wind farm integrated with VSC-HVDC,' ICEMS International conf., pp. 267-272, October 2013.

[27] N. K. Singh, and J.X. Carlsson, "Energization study of five- terminal multi-level HVDC converter station," in IEEE Power and Energy Society Conf. (PES), pp. 1-5, July 2013.

[28] J. Wu, S. Zhang, and D. Xu, "Modeling and control of multi-terminal HVDC with offshore wind farm integration and DC chopper based protection strategies," Industrial Electronics Society, IECON Annual IEEE Conf., pp.1013-1018, November 2013.

[29] Y. Li, W. Sun, Y-N, Chi, and L-J, Wei, "Research on offshore wind farm VSC-HVDC transmission system fault ride through issue," POWERCON International conf., pp. 2190-2195, October 2014.

[30] M. Mohammadi, M. Avendano- Mora, M. Barnes, and J. Y. Chan, “A study on Fault Ride through of VSC - connected offshore wind farms, , Power and Energy Society General Meeting (PES) Conf., pp. 1-5, July 2013.

[31] G. Ramtharan, A. Arulampalam, J. B. Ekanayake, F. M. Hughes, and N. Jenkins, "Fault ride through of fully rated converter wind turbines with AC and DC transmission,' IET Renewable Power Generation, vol. 3, no. 4, pp. 426 -438, December 2009.

[32] L. Xu and L. Yao, "DC Voltage control and power dispatch of a multiterminal HVDC system for integrating large offshore wind farms,', IET Renewable Power Generation, vol. 5, no. 3, pp. 223-233, May 2011.

[33] L. Xu and B. R. Anderson, "Grid Connection of large offshore wind farms using HVDC,'” Wind Energy, vol. 9, no. 3, pp. 371-382, 2006.

[34] L. Xu, L. Z. Yao, and C. Sasse, "Grid integration of large DFIG based wind farms using VSC transmission, " IEEE Trans. Power Syst., vol. 22, no. 3, pp. 976-984, 2007.

[35] B. Silva, C. L. Moreira, and H. Leite, "'Operation and Control of Multiterminal HVDC grids following the loss of an Onshore Converter," IEEE PES Conference on Innovative Smart Grid Technologies, pp. 1-8, April 2013. 
[36] A. Egea-Alvarez, A. Junyent-Ferre, O. Gomis-Bellmunt, J. Liang, J. Ekanayake, and N. Jenkins, "Operation and control of VSC-HVDC multiterminal grids for offshore wind,' Proceedings of Conference on Power Electronics and Applications, pp.1-9, 2011.

[37] J. Liang, O. Gomis-Bellmunt, J. Ekanayake, and N. Jenkins, "Control of multi-terminal VSC-HVDC transmission for offshore wind power,' European Conference on Power Electronics and Applications,' pp. 1$10,2009$.

[38] C. Feltes, H. Wrede, F. W. Koch, and I. Erlich, "Enhanced fault ridethrough method for wind farms connected to the grid through VSCBased HVDC transmission,', in IEEE Trans. Power Systems, 2009, vol. 24, no. 3, pp. 1537-1546.

[39] T. D. Vrionis, X. I. Koutiva, N. A. Vovos, and G. B. Giannakopoulos, "Control of an HVDC link connecting a wind farm to the grid for fault ride-through enhancement,' IEEE Transactions on Power Systems, vol. 22, no.4, pp. 2039-2047, 2007.

[40] W. Lu and B. T. Ooi, "DC overvoltage control during loss of converter in multiterminal voltage-source converter-based HVDC(M-VSCHVDC),', Power Delivery, IEEE Transactions on, vol. 18, no. 3, pp. $915-920$, July 2003.

[41] T. D. Vrionis, X. I. Koutiva, N. A. Vovos, and G. B. Giannakopoulos, "Control of an HVDC link connecting a wind farm to the grid for fault ride-through enhancement," IEEE Transactions on Power Systems, vol. 22, no. 4, pp. 2039 - 2047, Nov. 2007.

[42] K. H. Ahmed et al, "Fault ride through capability enhancement based on flywheel energy storage system for wind farms connected via VSC high voltage DC transmission,"' pp. 1-6, 2012.

[43] A. Arulampalam, G. Ramtharan, N. Caliao, J. Ekanayake and N Jenkins," Simulated Onshore-Fault Ride Through of Offshore Wind Farms Connected Through VSC HVDC," Wind Engineering, vol. 32, no. 2, pp. 103-114, 2008.

[44] Alstom, HVDC- Connecting to the future: Alstom, 2010.

[45] B. Jacobson, P. Karlsson, G. Asplund, L. Harnefors, and T. Jonsson, "VSC- HVDC Transmission with Cascaded Two-level Converters, ' Cigre B4 - 110, 2010.

[46] A. J. Beddard, "Factors Affecting the Reliability of VSC-HVDC for the Connection of Offshore Windfarms,' $\mathrm{PhD}$ thesis, The university of Manchester, UK, 2014.

[47] Guidance Notes for Power Park Developers (2007), "Grid Code Connection Conditions Compliance: Testing \& Submission Compliance Report - Issue 1.1,',

[48] A. Nachiappan, K, Sundararajan, and V. Malarselvam, "Curren controlled voltage source inverter using Hysteresis controller and PI controller,' EPSCICON International Conf., pp. 1-6, January 2012.

[49] M. Lafoz, I. Iglesias, C. Veganzones, and M. Visiers, "A novel double hysteresis-band current control for a three- level voltage source inverter, " IEEE Trans. On Power Electronics Specialists, vol. 1, pp. 21-26, 2000.

[50] A. J. Mahdi, W. H. Tang, L. Jiang, and Q. H. Wu, "A Comparative study on variable - speed operations of a wind generation system using vector control," EA4EPQ International Conf. on renewable energies and power quality, March 2010.

[51] L. X, and, L. Yao, "DC voltage control and power dispatch of a multiterminal HVDC system for integrating large offshore wind farms,', IET Renewable Power Generation Journal, vol. 5, pp. 223-233, May 2011. 